\title{
Finite element analyses predict the mechanical impact of cam-FAl surgery on ovine femurs
}

\section{Ghislain Maquer $^{1}$, Alexander Bürki ${ }^{1}$, Katja Nuss², Philippe K. Zysset ${ }^{1}$, Moritz Tannast²,3}

1 Institute for Surgical Technology and Biomechanics, University of Bern, Switzerland • 2 Musculoskeletal Research Unit, Vetsuisse Faculty, University of Zurich, Switzerland $\bullet{ }^{3}$ Department of Orthopaedic Surgery, Inselspital, University of Bern, Switzerland

\section{Introduction}

Cam-type femoroacetabular impingement (FAI) is induced in ovine hip to generate chondrolabral lesions as seen in human beings [1]. The surgical correction, however, may induce iatrogenic fractures.
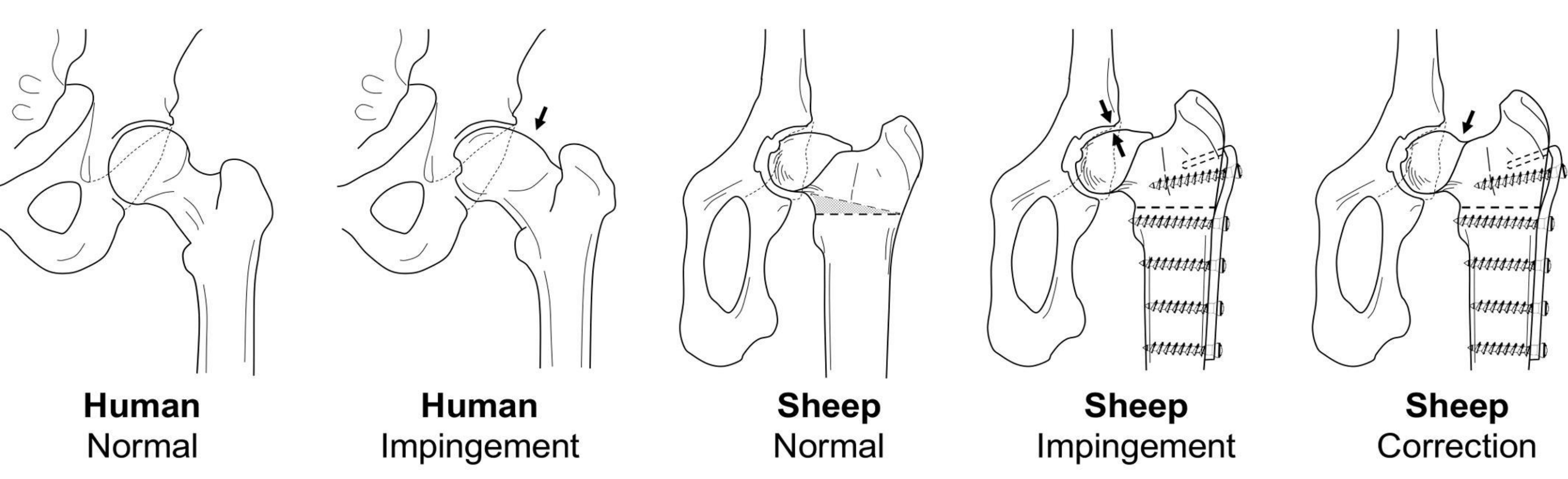

Aims:

- Assess the impact of the correction on ovine femoral strength.

- Evaluate the predictive value of finite element (FE) models based on quantitative computed tomography (QCT).

\section{Methods}

A. Eighteen femoral pairs were extracted from Swiss alpine sheep $(2.5 \pm 0.5 \mathrm{yrs}, 62 \pm 6 \mathrm{~kg})$. Three resection groups $(3,5,9 \mathrm{~mm}$ corresponding to $12 \%, 24 \%, 36 \%$ of the neck diameter) were created after correcting one femur of each pair. The samples were then scanned (QCT) with a calibration phantom.

B. The femurs ${ }^{1}$ were compressed via a servo-hydraulic device ${ }^{2}$. Linear bearings ${ }^{3}$ allowed lateral motions of the head. A load cell ${ }^{4}$ under the sample holder ${ }^{5}$ recorded the forces. A cap ${ }^{6}$ distributed the load on the head. The distal part was embedded in bone cement $^{7}$ after positioning the condyles ${ }^{8}$. The musculoskeletal axis $^{9-10}$ was aligned with the loading axis.
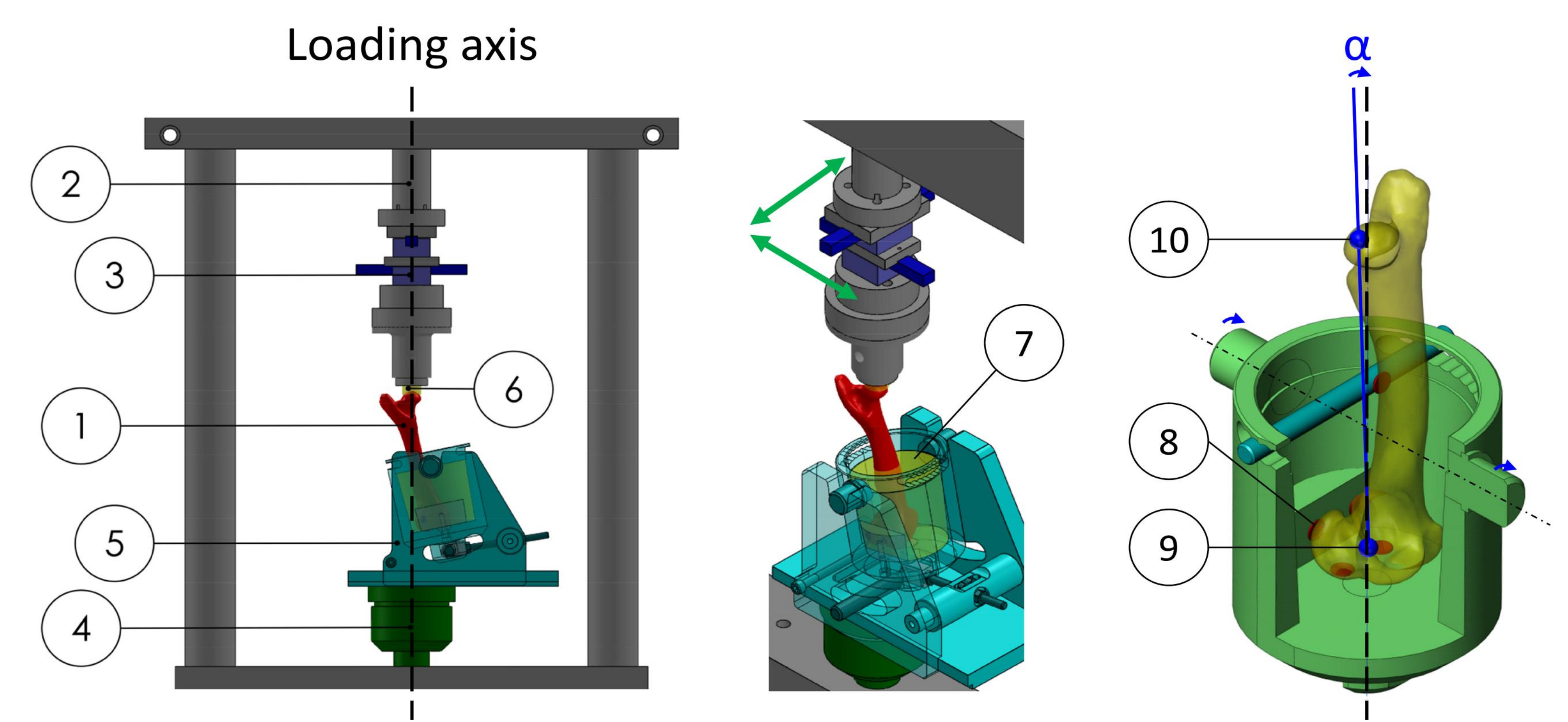

C. FE models of the proximal femurs were generated from the QCT data and similar tests were simulated. Cement blocks were added on the femoral head and under the shaft. Bone followed a validated material law featuring a damage variable mimicking the stiffness reduction owing to micro-cracks [2].
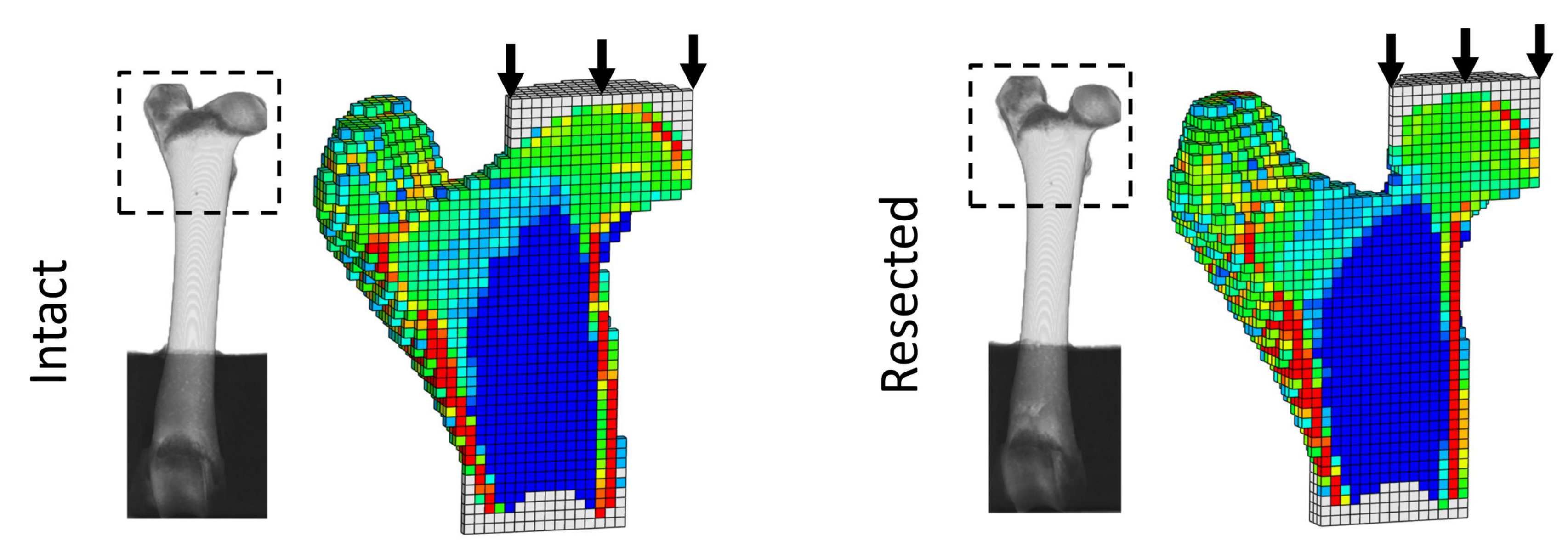

D. Failure loads and failure patterns were computed. The weakening of the resected femurs was evaluated relative to the intact contralateral side.

\section{Results}

Impact of the correction on ovine femoral strength

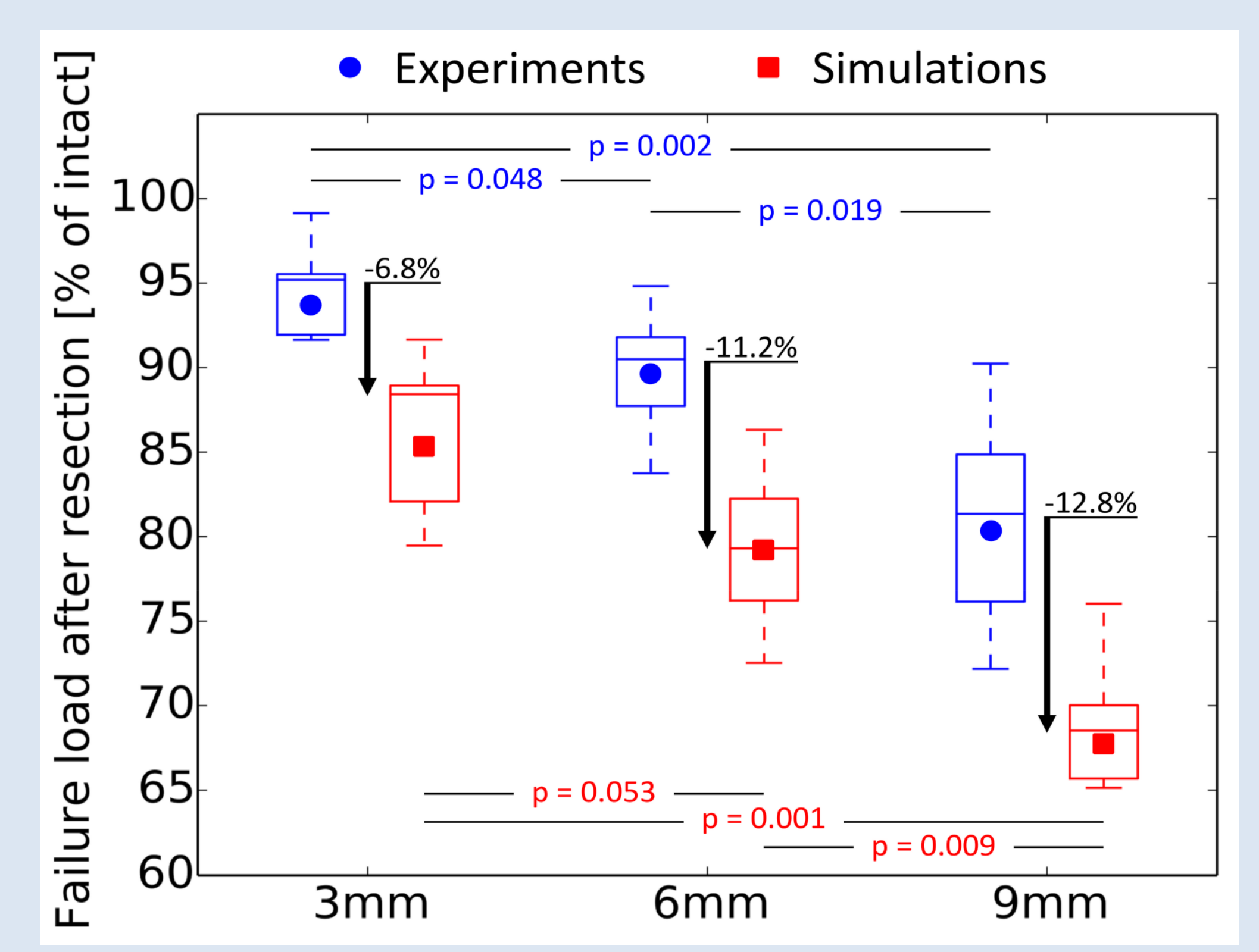

Fig 1. Larger defects significantly reduced the failure load, but the resection size had more impact on the FE predictions.

- Predictive value of the FE models
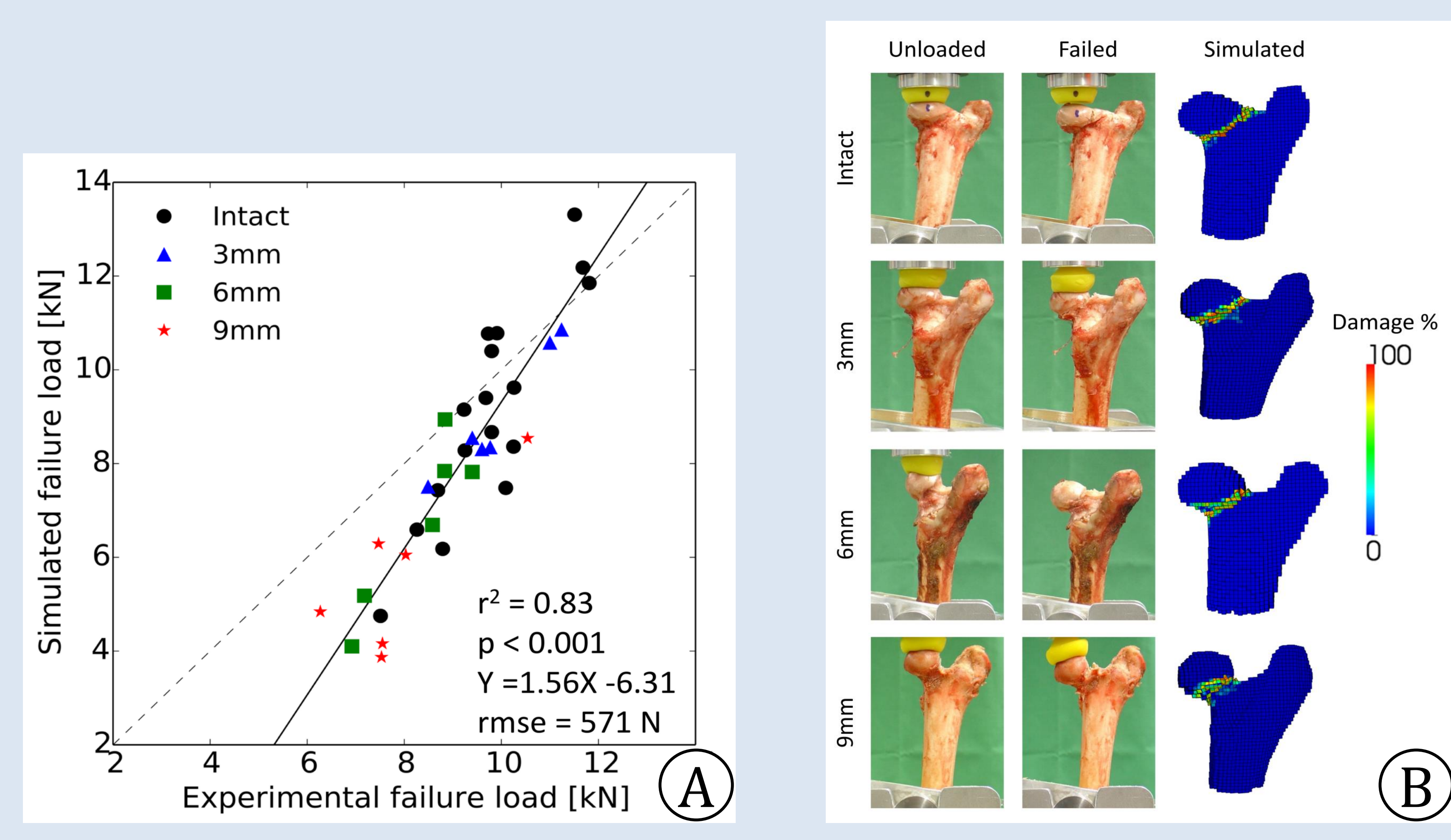

(B)

Fig2. A. High correlation between the simulated and experimental failure loads was established. B. Strong correspondences were observed between in-vitro and in-silico failure patterns.

\section{Conclusions}

More than $80 \%$ of the initial strength is preserved after a $36 \%$ neck resection. This is consistent with human data [3].

FE models catch the weakening of ovine femurs. The larger influence of the resection size may be due to modelling simplifications (cortex, trabecular orientation, material law).

The predictive value of the FE models is comparable to what is being done for intact human femurs $\left(\mathrm{r}^{2}=0.82-0.95\right)[4,5]$.

Based on pre-operative CT, FE models could provide patientspecific guidelines to prevent over-correction of cam-type FAI.

[1] Siebenrock KA . J Orthop Res. 2013;31(4):580-587. [2] Schwiedrzik JJ. Biomech Model Mechan. 2013;12(2):201-213. [3] Mardones RM. J Bone Joint Surg. Am. 2005;87(2):273-279. [4] Keyak JH. Clin Orthop Relat Res. 2005;437: 219-228. [5] Mirzaei M. Bone. 2014;64:108-114.

The project was possible via funding from the Swiss National Science Foundation and the Gebert Rüf Foundation. 